\title{
The effect of nitrogen content on the intergranular corrosion of ferritic stainless steel
}

\author{
Hu Pan ${ }^{1, a}$, Mao Honghuan ${ }^{2, b}$ and Yang Yitao ${ }^{3, c}$ \\ ${ }^{1,2,3}$ School of Materials Science and Engineering, Shanghai University, Shanghai 200072, China \\ a2731@shu.edu.cn, b970440413@qq.com, cyyt@staff.shu.edu.cn
}

Keywords: ferritic stainless; DL-EPR testing; nitrogen content; intergranular corrosion

Abstract. The intergranular corrosion behavior of 430 ferritic stainless, with $0.025 \%$ up to $0.065 \%$ nitrogen contents, was studied by DL-EPR testing, SEM and EDS to elucidate the influence of nitrogen. The results indicated that, with the increase of the nitrogen content in the steel, the susceptibility to intergranular attack became more serious, when the nitrogen content increased up to $0.045 \mathrm{wt} . \%$, the tendency was no more obvious; The Ra values increased with the extension of sensitization time, low nitrogen content has a beneficial effect on inhibition of this trend; The precipitation of $\mathrm{V}(\mathrm{C}, \mathrm{N})$ improved the intergranular corrosion resistance to some extent, especially in the stainless steels contained low nitrogen.

\section{Introduction}

The intergranular corrosion (IGC) of stainless steel is common in austenitic stainless steel. However, with the fluctuation of the price of nickel in the world in recent years, the application of ferritic stainless steel(FSS) is becoming more and more popular because it contains low nickel or no nickel. The IGC of ferritic stainless steel has received increased attention of researchers consequently. Jin Ho Park et al. ${ }^{[1]}$ studied effect of $\mathrm{Zr}$ addition on intergranular corrosion of low-chromium ferritic stainless steel. It was concluded that the addition of $\mathrm{Zr}$ as a stabilizer to low-Cr FSS formed a mixture of $\mathrm{ZrC}+\mathrm{Fe}_{23} \mathrm{Zr}_{6}$ precipitates which can effectively prevent IGC in two ways: as a strong carbide former to suppress the formation of $\mathrm{Cr}$-carbide and as a diffusion barrier against the diffusion of solute $\mathrm{Cr}$ towards the grain boundary. Jin Ho Park et al. ${ }^{[2]}$ also put forward some other concepts to prevent the IGC of FSS such as adding Mo, Mn and Si to low-Cr ferritic stainless, which formed $\mathrm{CMn}_{4} \mathrm{MoSi}$ intermetallic compounds, acting not only as carbon trap sites but also as diffusion barrier against solute $\mathrm{Cr}$ diffusion toward grain boundaries. Jeong Kil Kim et al. ${ }^{[3]}$ did some research on the effect of chromium content on intergranular corrosion and precipitation of Ti-stabilized ferritic stainless steels and found that the increase in $\mathrm{Cr}$ content improved IGC resistance as temperature and time for the sensitization became higher and longer, respectively, but it did not prevent IGC. The $\mathrm{Cr}$ segregation was proposed to explain the $\mathrm{Cr}$ depletion for the cause of IGC in Ti-stabilized Cr FSS.

It has been reported that nitrogen additions plays lots of benefit roles in stainless steels. With an increase in nitrogen content in stainless steels, the corrosion resistance such as pitting corrosion(particularly in the presence of molybdenum) ${ }^{[4]}$, crevice corrosion ${ }^{[5]}$ and stress corrosion cracking $^{[6]}$ has been significantly improved. Nevertheless, limited work has been conducted on the effect of nitrogen content on the IGC of FSS. Based on the SUS 430 ferritic stainless steel, double loop electrochemical potentiokinetic reactivation (DL-EPR) test was applied to determine the nitrogen content on the susceptibility to IGC of ferritic stainless steel. This paper could be an important reference on related production in the future.

\section{Experimental procedures}

The materials used in this experiment were about $2 \mathrm{~mm}$ thick hot-rolled sheets of ferritic stainless steels, annealed at $850{ }^{\circ} \mathrm{C}$ for $1 \mathrm{~h}$ after hot rolling and then quenched by air. The chemical compositions of the experimental alloys with three different nitrogen contents were listed in Table 1, coded as sample N1, N2 and N3 by their nitrogen content range. 
Table 1. Chemical compositions of the specimens(wt.\%)

\begin{tabular}{ccccccc}
\hline No. & $\mathrm{C}$ & $\mathrm{Si}$ & $\mathrm{Mn}$ & $\mathrm{Cr}$ & $\mathrm{V}$ & $\mathrm{N}$ \\
\hline $\mathrm{N} 1$ & 0.025 & 0.15 & 0.70 & 16.15 & 0.15 & 0.025 \\
N2 & 0.025 & 0.15 & 0.70 & 16.15 & 0.15 & 0.045 \\
N3 & 0.025 & 0.15 & 0.70 & 16.15 & 0.15 & 0.065
\end{tabular}

Sensitizing treatment was performed at $950{ }^{\circ} \mathrm{C}$ for 10,30 and 60 min. Rectangular test specimens $(10 \times 10 \times 2 \mathrm{~mm})$, with their surface water polished on $\mathrm{SiC}$ paper up to 2000 \# polishing grade, were sealed by epoxy and contacted electrically with copper line. The DL-EPR test was conducted in a $0.1 \mathrm{~mol} / \mathrm{L} \mathrm{H}_{2} \mathrm{SO}_{4}$ solution with the addition of $0.0025 \mathrm{~mol} / \mathrm{L} \mathrm{KSCN}$ after grinding the surface of the specimen with $\mathrm{SiC}$ paper 2000\#. The specimen was anodically polarized from the corrosion potential to $0.4 \mathrm{~V}_{\mathrm{SCE}}$ at a scan rate of $1.67 \mathrm{mV} / \mathrm{s}^{[7]}$. In this polarization, the active dissolution occurs, and then a passive layer forms on the entire surface. At $0.4 \mathrm{~V}_{\mathrm{SCE}}$, the polarization was reversed at the same scan rate, and the testing was finished at the corrosion potential which was initially measured. The IGC tendency was evaluated by measuring the degree of sensitization (DOS), which is the ratio( $\mathrm{Ra}$ ) between the maximum current density in the anodic scan loop (Ia) and that in the reverse scan loop (Ir) ${ }^{[1]}$. In general, the bigger the Ra, the more sensitive the IGC. The microstructure of the specimens was examined for IGC after and without the DL-EPR test. At least three independent DL-EPR tests were performed per specimen for reproducibility and reliability.

\section{Experimental results and discussion \\ DL-EPR test}

The EPR curves of all specimens sensitized at $950{ }^{\circ} \mathrm{C}$ for $10-60 \mathrm{~min}$, as shown in Fig.1, whose electrochemical parameters are listed in table 2. It is visible from table 2 that the difference among the Ia values of different samples was negligible because the surface of the working electrode was under uniform corrosion in the polarization so that the current remained stable ${ }^{[8]}$. It was also informed from table 2 that the value of the Ra increased with the increase of nitrogen content. When sensitized at 950 ${ }^{\circ} \mathrm{C}$ for $10 \mathrm{~min}$, the Ra value of $\mathrm{N} 1$ sample (0.185) was obviously smaller than that of the other two samples'(0.304 and 0.329, respectively). When the sensitization time was increased up to $30 \mathrm{~min}$, the Ra values of all specimens were larger than that of 10 min's. However, in this case, the Ra value of N1 sample was a little larger, the other two samples were completely different $(0.02$ for N1, 0.035 and 0.039 for $\mathrm{N} 2$ and $\mathrm{N} 3$ respectively), which indicated that the low nitrogen content restrained the tendency to intergranular corrosion to some extent. As long as sensitized for $60 \mathrm{~min}$, the growth of N1 sample was significantly larger than that of the others', which inferred that the low nitrogen content cannot avoid intergranular corrosion in this condition because of the extension of sensitization time. Meanwhile, the susceptibility to intergranular corrosion of the samples with high nitrogen content was serious under the experimental conditions of sensitization for $30 \mathrm{~min}$, extending the sensitization time just made the tendency more clear. Hu Fangjian et al. ${ }^{[9]}$ studied the susceptibility of ferritic stainless steels to intergranular corrosion and found that the observation of surface after EPR testing was necessary because electrochemical measurement had shortcomings on the research on intergranular corrosion of ferritic stainless steel. Therefore, the Ra value can only reflect the material's tendency to intergranular corrosion, whether intergranular corrosion depended on the following SEM surface morphology. 

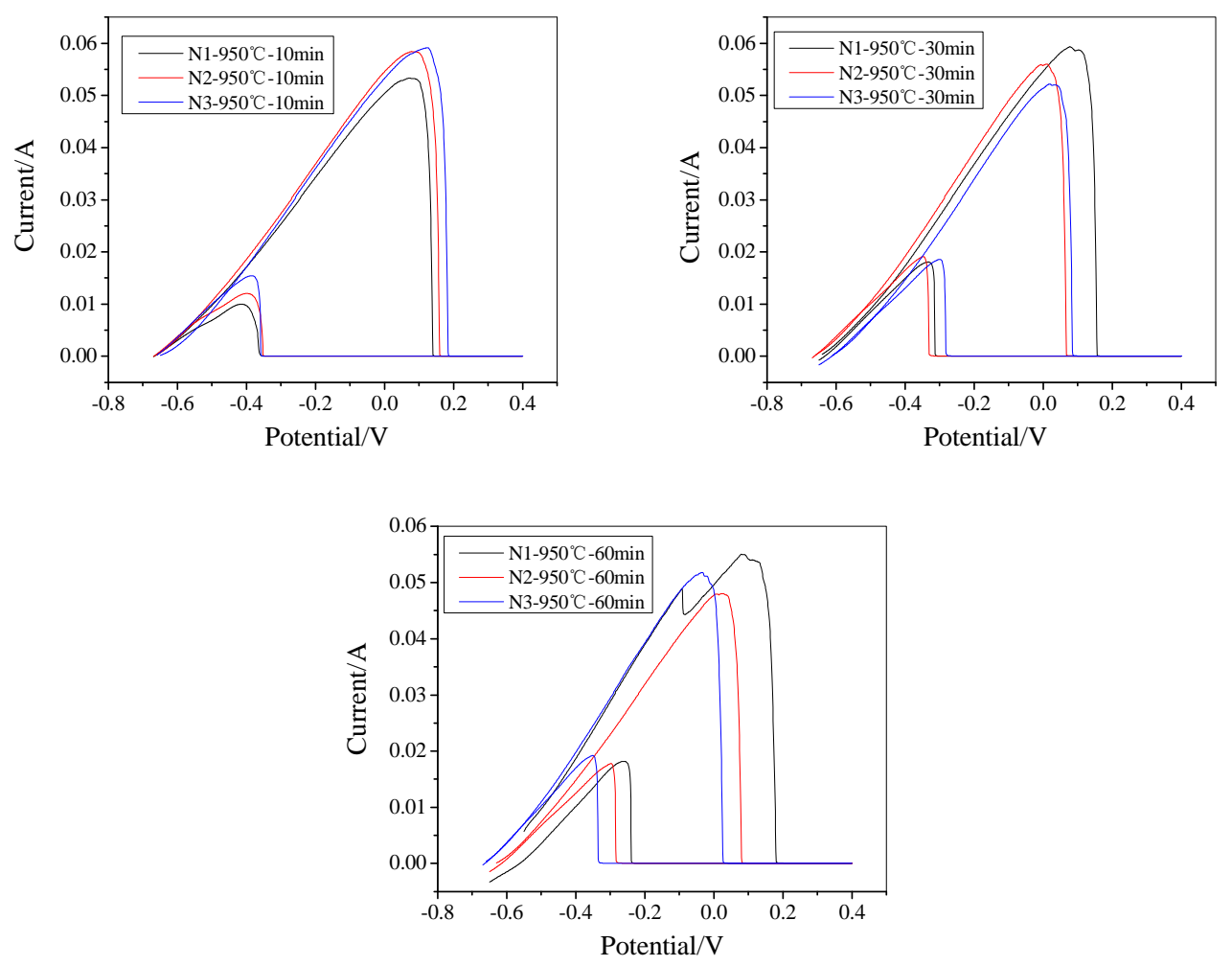

Fig.1 ERP curves of all specimens sensitized at $950{ }^{\circ} \mathrm{C}$ for $10-60 \mathrm{~min}$

Table 2 Electrochemical parameters obtained in DL-EPR test

\begin{tabular}{cccccccccc}
\hline condition & \multicolumn{3}{c}{$\mathrm{N} 1$} & \multicolumn{3}{c}{$\mathrm{N} 2$} & \multicolumn{3}{c}{$\mathrm{N} 3$} \\
\cline { 2 - 9 } & $I_{r} / \mathrm{A}$ & $I_{a} / \mathrm{A}$ & $R a$ & $I_{r} / \mathrm{A}$ & $I_{a} / \mathrm{A}$ & $R a$ & $I_{r} / \mathrm{A}$ & $I_{a} / \mathrm{A}$ & $R a$ \\
\hline $\begin{array}{c}950^{\circ} \mathrm{C} \\
-10 \mathrm{~min}\end{array}$ & 0.0099 & 0.0533 & 0.185 & 0.0120 & 0.0584 & 0.205 & 0.0154 & 0.0591 & 0.260 \\
$950^{\circ} \mathrm{C}$ & 0.0180 & 0.0592 & 0.304 & 0.0190 & 0.0559 & 0.339 & 0.0185 & 0.0521 & 0.355 \\
$-30 \mathrm{~min}$ & & & & & & & & & \\
$950^{\circ} \mathrm{C}$ & 0.0181 & 0.0549 & 0.329 & 0.0177 & 0.0480 & 0.368 & 0.0191 & 0.0517 & 0.369 \\
$-60 \mathrm{~min}$ & & & & & & & & & \\
\hline
\end{tabular}

Fig. 2 shows the SEM surface morphology of specimen after EPR testing. It can be seen that when sensitized at $950{ }^{\circ} \mathrm{C}$ for $10 \mathrm{~min}$, the grain boundary of all steels was not observed in the surface, but the corrosion pit appeared only in the N2 and N3 sample. In the front of ERP testing, polishing was not conducted, however, the scratch was not being discovered, which indicated that all materials were under uniform corrosion. It is visible form Table 2 that under the sensitization time of $10 \mathrm{~min}$, the Ra values of N1 sample was greatly different form that of the others', the intergranular corrosion of N2 and N3 samples were not observed in the SEM photos, which can be inferred that the susceptibility to intergranular corrosion of ferritic stainless steel had no quantitative relationship with reactivation rate $\mathrm{Ra}$. When the sensitization time was increased up to $30 \mathrm{~min}$, the surface of N1 sample was a little different from that of sensitization time of $10 \mathrm{~min}$ 's, only a small part of area existed grain boundary because of the tiny difference between the two conditions(Fig.2.d); however, obvious grain boundaries were observed in the $\mathrm{N} 2$ and $\mathrm{N} 3$ samples, which showed that low nitrogen content has a beneficial effect on the intergranular corrosion to a certain degree. Once the sensitization time increased to 60 minutes, the N1 sample performed poor intergranular corrosion, the grain boundary was more evident than before, but its width and depth was far less than the other two groups in this condition, showing the beneficial effect of low nitrogen content once again; the surface of N2 and N3 samples was similar from each other, only the width and depth became larger. Thus it can be concluded that low nitrogen content has a beneficial effect on the intergranular corrosion of ferritic 
stainless steel, and the beneficial effect became more significant with the extension of sensitization time, especially after $30 \mathrm{~min}$.
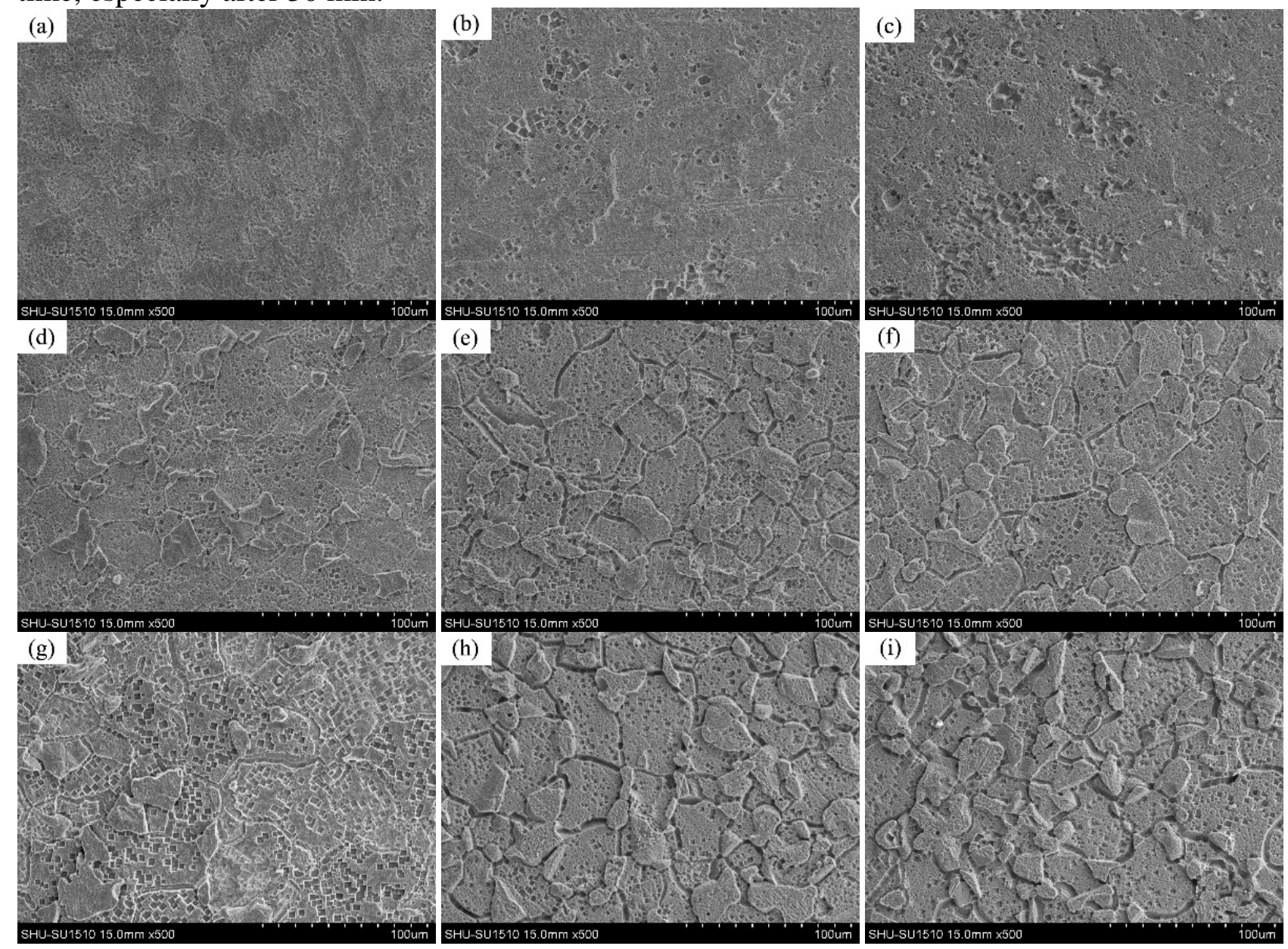

Fig.2 Surface morphology of specimen after EPR testing

(a)N1-10 min; (b)N2-10 min; (c)N3-10 min; (d)N1-30 min; (e)N2-30 min; (f)N3-30 min; (g)N1-60 min; (h)N2-60 min; (i)N3-60 min

\section{Analysis of the precipitation}

The surface morphologies of $\mathrm{N} 1$ and $\mathrm{N} 2$ specimen without EPR testing were presented in Fig.3(From above, the difference between N2 and N3 sample was not obvious, thus only N1 and N2 were listed). It is seen from the Fig.3.a that when sensitized at $950{ }^{\circ} \mathrm{C}$ for 30 min, only a small part of precipitation was observed in the grain boundary, which was made up of $\mathrm{Fe}, \mathrm{Cr}, \mathrm{V}, \mathrm{C}$ and $\mathrm{N}$, identified by EDS(Fig.4.a). Because of its small size and its less location, no Chromium depleted zone was found, and grain boundary was not observed after EPR testing(Fig.2.d); meanwhile, a lot of particles appeared around the grain boundary of $\mathrm{N} 2$ sample, identified as $\mathrm{Fe}$ and $\mathrm{Cr}$ carbide, According to the results in Fig.2.e, the number of the carbide was enough to produce Chromium depleted zone, followed by intergranular corrosion. When the sensitization time increased to $60 \mathrm{~min}$, the composition of precipitation of N1 sample was the same as before, only its size and quantity were greater, therefore, intergranular corrosion was unavoidable. In this condition, the grain boundary characteristics of $\mathrm{N} 2$ sample was similar to that of the former, the Chromium depleted zone was more serious with the extension of sensitization time, the result reflected in the EPR testing was more obvious.

$\mathrm{N}$ as a interstitial element existing in ferritic stainless steel, should act as similar as $\mathrm{C} . \mathrm{Cr}_{23}(\mathrm{C}, \mathrm{N})_{6}$ precipitates around the grain boundary when being sensitization treated. However, precipitation contained $\mathrm{N}$ only appeared in steel with low nitrogen content, because of the presence of a certain amount of V. It was concluded by Chen Siyue ${ }^{[10]}$ that $\mathrm{V}(\mathrm{C}, \mathrm{N})$ precipitated in ferritic stainless steel with $\mathrm{N}$ content, indicating that $\mathrm{V}$ has a beneficial effect on stabilizing $\mathrm{C}$ and $\mathrm{N}$ to some extent. It can also be seen from this experiment that the beneficial effect of $\mathrm{V}$ was better when the nitrogen content 
was lower. As long as the nitrogen content was increased up to $0.045 \mathrm{wt} . \%$, the beneficial effect no longer existed and followed by intergranular.
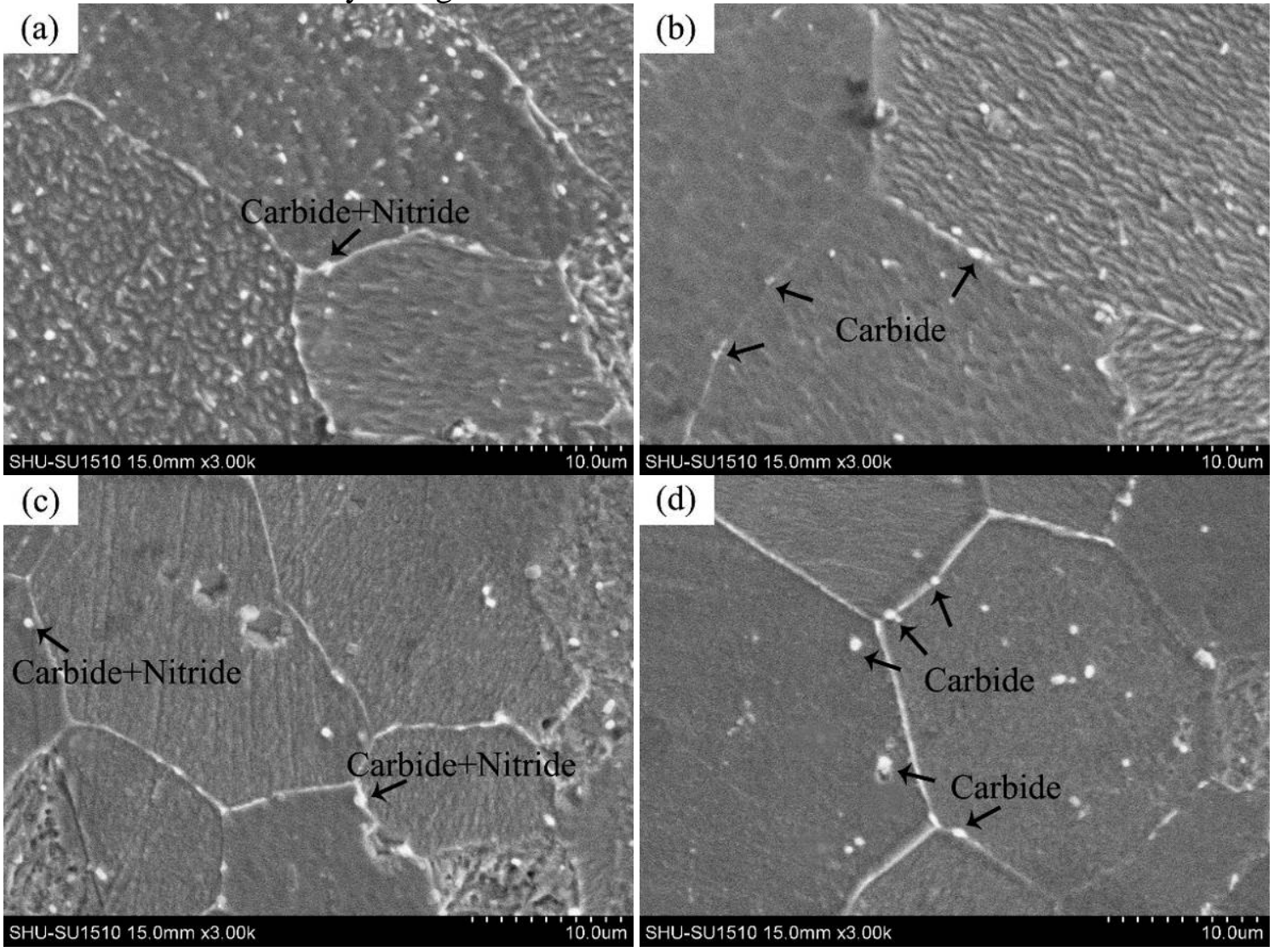

Fig.3 Surface morphology of specimen without EPR testing

(a)N1-30 min; (b)N2-30 min; (c)N1-60 min; (d)N2-60 min

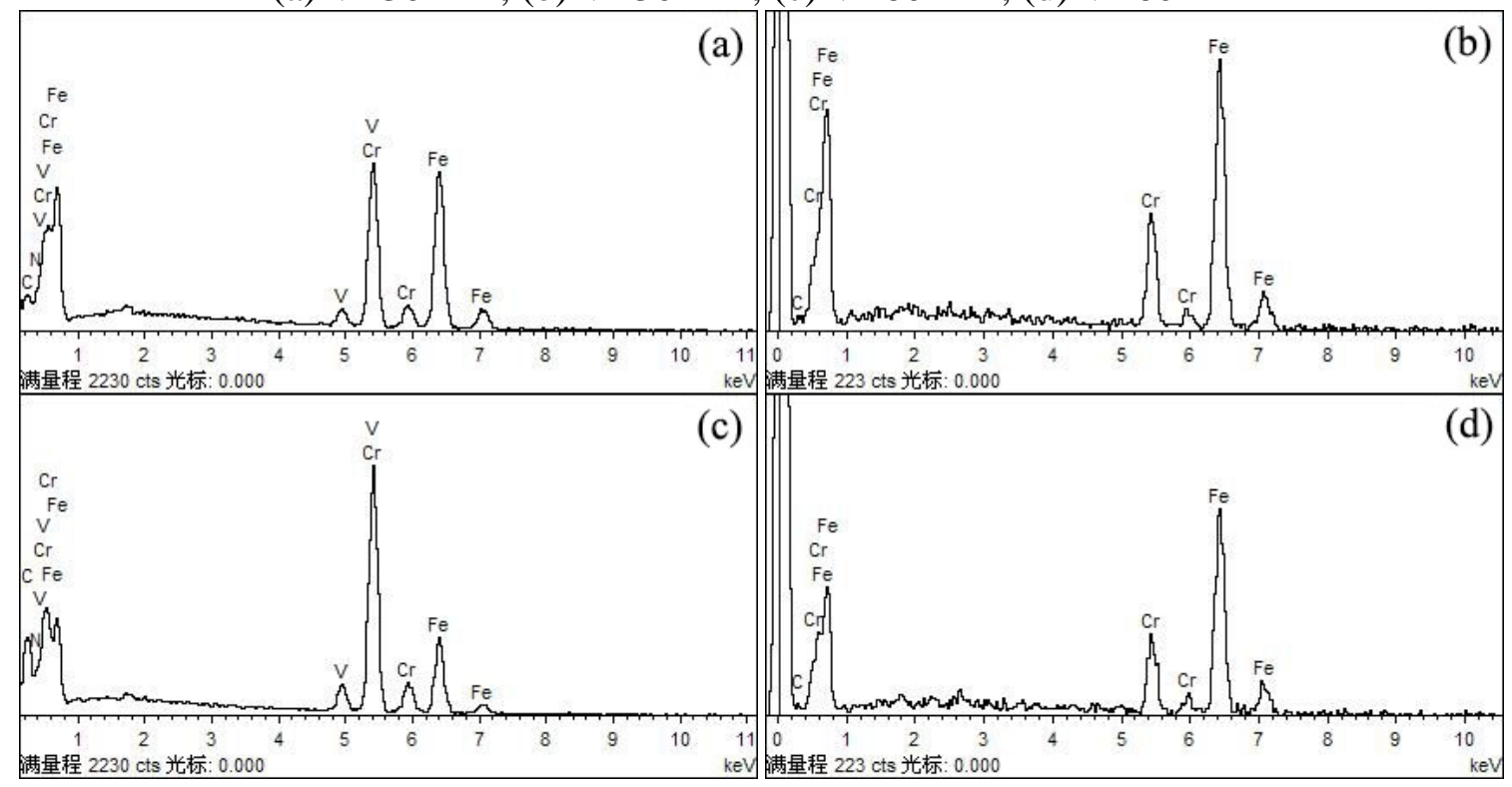

Fig.4 EDS results of carbide contented in Fig.3

(a)N1-30 min; (b)N2-30 min; (c)N1-60 min; (d) N2-60 min

\section{Conclusion}

1 With the increase of the nitrogen content in the steel, the susceptibility to intergranular attack became more serious, when the nitrogen content increased up to $0.045 \mathrm{wt} . \%$, the tendency was no more obvious. 
2 The Ra values increased with the extension of sensitization time, low nitrogen content has a beneficial effect on inhibition of this trend.

3 The precipitation of $\mathrm{V}(\mathrm{C}, \mathrm{N})$ improved the intergranular corrosion resistance to some extent, especially in the stainless steels contained low nitrogen.

\section{References}

[1] Jin Ho Park, Jeong Kil Kim and Bong Ho Lee, Effect of Zr addition on intergranular corrosion of low-chromium ferritic stainless steel, Scripta MATERIAL. 76(2014)77-80.

[2] Jin Ho Park, Hyung Suk Seo, Kyoo Young Kim, Alloy Design to Prevent Intergranular Corrosion of Low-Cr Ferritic Stainless Steel withWeak Carbide Formers, Journal of The Electrochemical Society. 162(2015)412-418.

[3] Jeong Kil Kim, Yeong Ho Kim, Jong Sub Lee, Effect of chromium content on intergranular corrosion and precipitation of Ti-stabilized ferritic stainless steels, Corrosion Science. 52(2010)1847-1852.

[4] R.F.A.Jargelius-Pettersson, Electrochemical investigation of the infuence of nitrogen alloying on pitting corrosion of austenitic stainless steels, Corrosion Science. 41(1999)1639-1664.

[5] Sedriks, A.J, Role of Sulfide Inclusions in Pitting and Crevice Corrosion of Stainless Steels, International metals reviews. 28(1983) 295-307.

[6] A. Poonguzhali, M.G. Pujar, U. Kamachi Mudali, Effect of Nitrogen and Sensitization on the Microstructure and Pitting Corrosion Behavior of AISI Type 316LN Stainless Steels, Journal of Materials Engineering and Performance. 22(2013)1170-1178.

[7] Jeong Kil Kim, Yeong Ho Kim, Sang Ho Uhm, Intergranular corrosion of Ti-stabilized 11 wt\% $\mathrm{Cr}$ ferritic stainless steel for automotive exhaust systems, Corrosion Science. 51(2009) 2716-2723.

[8] Xiaofei Yu, Shenhao Chen, Ying Liu, A study of intergranular corrosion of austenitic stainless steel by electrochemical potentiodynamic reactivation, electron back-scattering diffraction and cellular automaton, Corrosion Science. 52(2010)1939-1947.

[9] HU Fang-jian, WUYu-qin, ZHONG Xiang-yu, SUSCEPTIBILITY OF FERRITIC STAINLESS STEELS TO INTERGRANULAR CORROSION, CORROSION SCIENCE AND PROTECTION TECHNOLOGY. 21(2009)110-112.

[10] Chen Siyue, Zhang Xin, Yang Yitao, The influence of carbon and nitrogen on high temperature performance of vanadium containing ferritic stainless steel, MATERIAL SCIENCE \&TECHNOLOGY. 23(2015)75-82. 